\section{Ciência pós-normal e comunidades ampliadas de pares face aos desafios ambientais}

\section{Post-normal science and extended peer communities in the face of environmental challenges}

Silvio Funtowicz* Jerry Ravetz**

* Membro da European Commission Joint Research Centre/Institute for Systems, Informatics and Safety, TP 650 21020 Ispra (VA), Itália e-mail: silvio.funtowicz@jrc.it

** PhD em matemática, diretor da Research Methods Consultancy, em Londres. e-mail: jrravetz@compuserve.com

Tradução: Jaime Larry Benchimol. Revisão técnica: Carlos Machado de Freitas.
FUNTOWICZ, S. e RAVETZ, J : 'Ciência pós-normal e comunidades ampliadas de pares face aos desafios ambientais

História Ciências Saúde-Manguinhos, IV(2): 219-230 jul.-out. 1997.

Os novos problemas relacionados a riscos e ao meio ambiente têm aspectos comuns que os distinguem dos problemas científicos tradicionais: os fatos são incertos, os valores, controvertidos, as apostas, elevadas e as decisões, urgentes. Chamamos de ciência pós-normal a estratégia de resolução de problemas adequada a esse contexto. A função essencial de controle de qualidade e avaliação crítica não pode mais ser desempenhada por um corpo restrito de especialistas. O diálogo sobre a qualidade e a formulação de políticas devem ser estendidos a todos os afetados pela questão, que formam o que chamamos de "comunidade ampliada dos pares".

PALAVRAS-CHAVE: incerteza, qualidade, complexidade, ciência pós-normal, comunidades ampliadas de pares.

FUNTOWICZ, S. e RAVETZ, J.: 'Post-normal science and extended peer communities in the face of environmental challenges'. História, Ciências, Saúde-Manguinhos, IV(2):219-230 jul.-out. 1997.

The new issues of risk and the environment have common features that distinguish them from traditional scientific problems: uncertain facts, values in dispute, bigh stakes, and a pressing need for decision-making. The problem-solving strategy appropriate to this context can be called post-normal science. The essential function of quality assurance and critical assessment can no longer be performed only by a restricted corps of insiders. The dialogue on quality, along with that on policy, must be extended to all those who have a stake in the issue, that is, to the extended peer community.

KEYWORDS: uncertainty, quality,

complexity, post-normal science, extended peer-community. 


\section{Introdução}

D oucos ainda duvidam de que a cultura tecnológica moderna tenha alcançado um momento decisivo, e que precise mudar consideravelmente para que possamos lidar com os problemas relativos ao meio ambiente. Talvez seja mais difícil aceitar a idéia de que a ciência também deva mudar, pois, até agora, foi tida como mola propulsora do progresso tecnológico. As questões do meio ambiente impõem-lhe novas tarefas. Além da descoberta e aplicação de fatos científicos, requer realizações fundamentais destinadas a remediar as patologias de nosso sistema industrial. Não necessitamos mais do ideal de uma ciência despojada de valores, neutra do ponto de vista ético, nem devemos acreditar que dos fatos descobertos pela ciência decorram automaticamente decisões políticas racionais e corretas. Um método novo, baseado no reconhecimento da incerteza, da complexidade e da qualidade, guiará o novo empreendimento científico que chamamos de "ciência pós-normal".

Nossa abordagem é original no que diz respeito à ênfase nos conceitos de incerteza, complexidade e qualidade. Anteriormente, tais conceitos foram excluídos da representação da ciência vigente entre pesquisadores, filósofos e popularizadores. Tradicionalmente, imaginava-se que a ciência fazia avançar continuamente um conhecimento seguro e um controle eficiente sobre o mundo natural. Hoje, visualiza-se a ciência como algo que põe em confronto complexidades, que lida com incertezas e defronta decisões tecnológicas e ambientais urgentes, em escala local e global. O controle da qualidade dos resultados da pesquisa nesse contexto científico novo e mais amplo não pode mais ser delegado a comunidades isoladas de especialistas. Precisa ser renovado e enriquecido. O diálogo a respeito da qualidade, juntamente com aquele concernente às políticas científicas, deve ser estendido a

${ }^{1}$ Sistema Nusap: Numeral, Unit, Spread, Assessment and Pedigree System Trata-se de um esquema projetado para ser um sistema robusto de notações para expressar e comunicar incertezas em informações quantitativas. todos os afetados por determinada questão, desde que estejam comprometidos com um debate genuíno. Formam o que chamamos de "comunidade ampliada dos pares". O método que desenvolvemos para estimar e expressar a qualidade das informações técnicas em termos de suas incertezas características (sistema Nusap) ${ }^{1}$ facilita a avaliação crítica delas e contribui para o controle de qualidade exercido pelas comunidades ampliadas de pares que enfrentam problemas ambientais através da prática da ciência pós-normal (Funtowicz e Ravetz, 1990).

\section{Reinvasão do laboratório pela natureza}

Latour (1988) retratou bem o lugar da ciência no mundo industrializado ao mostrar Pasteur estendendo seu laboratório a 
toda zona rural francesa e, assim, a conquistando para a ciência e para si próprio. A natureza passou a ser abordada não mais como algo selvagem e ameaçador, mas, sim, passível de ser domesticado e tornado útil para a humanidade através da ciência. O milagre da ciência natural moderna reside na possibilidade de estender a experiência de laboratório - o estudo de um fragmento que foi isolado da natureza e conservado artificialmente puro, estável e reprodutível - à compreensão e ao controle da natureza em estado bruto. Juntas, a tecnologia e a medicina tornaram-na previsível e, em parte, controlável, permitindo que muita gente desfrutasse de uma vida mais segura e confortável que a vigente em qualquer outra época da história. O lado adverso deste feito é que ele pode muito bem ser insustentável não apenas em termos de eqüidade como de sobrevivência.

O método científico e o conhecimento técnico esotérico dos especialistas sobrepuseram-se a todas as outras modalidades de conhecimento, inclusive da natureza. Foram destituídas de sua autoridade a experiência do senso comum e as habilidades herdadas que os povos usavam para viver e fazer coisas. Foram destronadas pelos objetos teoricamente construídos do discurso científico que são necessários para se lidar com coisas invisíveis como micróbios, átomos, genes e quasares. Embora a ciência seja formalmente democrática, já que não há mais barreiras formais ao treinamento de seus praticantes, é, na verdade, prerrogativa daqueles que podem seguir educação prolongada e protegida e, portanto, dos grupos sociais a que pertencem esses indivíduos. Por uma tradição que deriva do iluminismo do século XVIII, a racionalidade subjacente às decisões públicas deve se apresentar como científica. Assim, intelectuais que dominam o estilo científico - acima de todos os economistas - passaram a ser encarados como autoridades supremas, detentoras e provedoras de sabedoria prática. Disseminou-se universalmente a suposição de que a expertise científica é o componente crucial da tomada de decisões concernentes quer à natureza quer à sociedade.

Os próprios poderes que a ciência criou engendraram uma nova relação dela com o mundo. O laboratório foi muito além da intervenção em pequena escala tipificada pela conquista do carbúnculo por Pasteur. Já não nos limitamos a observar os distúrbios familiares do ambiente natural provocados pelas modernas práticas industriais e agrícolas. A metodologia para lidar com os novos problemas não pode ser a mesma que ajudou a criá-los. O sucesso da ciência tradicional residia, em grande parte, no poder de fazer abstração das incertezas nos conhecimentos e valores. Isso se revela na tradição dominante de ensino da ciência, que se apóia num universo de fatos inquestionáveis, apresentados dogmaticamente e assimilados por estudantes acríticos. A expertise científica 
conduziu-nos a dilemas políticos que ela não consegue resolver sozinha. Não é só o controle e a previsibilidade que perdemos. Agora nos deparamos com radical incerteza, com a ignorância e com dúvidas éticas no âmago das questões que dizem respeito à política científica. Para compreender as novas tarefas e métodos da ciência, devemos inverter a metáfora de Latour e imaginar que a natureza invade agora o laboratório.

\section{Ciência pós-normal}

Os problemas atuais de saúde - ao nível individual, comunitário e ambiental - têm características comuns que os distinguem dos problemas científicos tradicionais. Sua escala é planetária e seu impacto, de longa duração. Os fenômenos são novos, complexos, variáveis e, com freqüência, mal compreendidos. Dados sobre seus efeitos, e dados para determinar as linhas de base de sistemas "não perturbados" mostram-se totalmente inadequados. Em geral, a ciência não fornece teorias bem fundamentadas em experimentos para explicar e prever esses problemas novos. Com freqüência, só é capaz de prover modelos matemáticos e simulações computadorizadas que não podem ser testados por métodos científicos tradicionais. Com base nesses aportes científicos tão incertos, decisões políticas devem ser tomadas, e com certa urgência. Assim sendo, as políticas destinadas a solucionar os problemas de meio ambiente não podem ser determinadas à luz de predições científicas; apóiam-se apenas em cálculos políticos.

Adotamos o termo "pós-normal" para caracterizar a ultrapassagem de uma era em que a norma para a prática científica eficaz podia ser a rotineira resolução de quebra-cabeças (Kuhn, 1962), ignorandose as questões mais amplas de natureza metodológica, social e ética suscitadas pela atividade e por seus produtos. Os principais problemas científicos não podem mais derivar só da curiosidade dos cientistas ou dos interesses da defesa e da indústria. A comunidade de pesquisadores não pode se dar ao luxo de protelar a investigação de problemas até que tenham a esperança de obter sucesso. Face a questões relacionadas a uma definição ampla de saúde, precisa dar o melhor de si, por mais complexos que sejam os problemas e incertas as soluções, e sejam quais forem as implicações políticas. Porque esses novos problemas em geral são criados quando os fatos são incertos, os valores, controversos, as apostas, elevadas, e as decisões, urgentes. Além do mais, quando a pesquisa é reclamada, é preciso primeiro definir o problema a estudar, e isso dependerá de quais aspectos sobressaem mais. Portanto, considerações políticas coagem as classes de possíveis resultados que podem ser obtidos e, por conseguinte, as classes de opções políticas que teriam respaldo científico. Em geral, a 
oposição tradicional entre fatos "duros" e valores "brandos" aparece invertida na situação de ciência pós-normal. Aqui nos deparamos com decisões que são "duras" em todos os sentidos, e para as quais os aportes científicos são irremediavelmente "brandos".

As limitações inerentes às estratégias tradicionais de resolução de problemas são reveladas por uma característica estrutural dos novos tipos de problemas: as decisões dependem de avaliações de estados futuros do ambiente natural, dos recursos e da sociedade humana, mas não se conhecem, nem se podem conhecer, em detalhes nenhum destes estados. Além disso, as irremediáveis incertezas embutidas nos conhecimentos relevantes para a formulação de políticas somamse às complexidades morais decorrentes da invasão dos domínios do sagrado e do privado pelos poderes da ciência. Os casos mais notáveis são a tecnologia reprodutiva e a pesquisa científica que necessita infligir dados a seres sensíveis. Nessas novas circunstâncias, caracterizadas por incertezas radicais de todos os tipos, está emergindo um novo tipo de percepção da resolução de problemas.

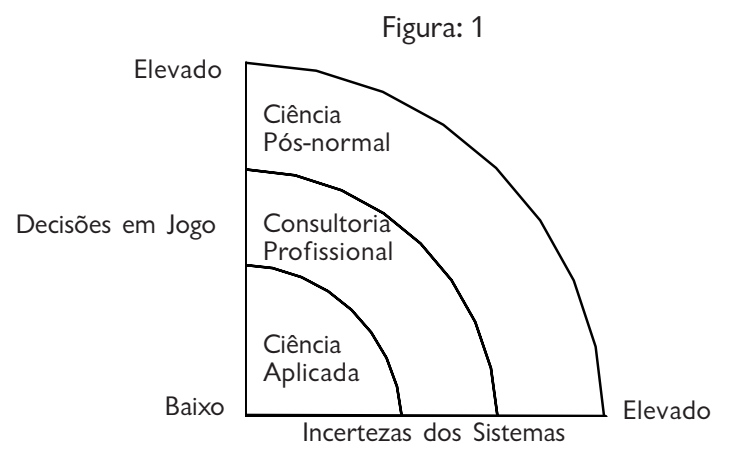

Podemos analisar os diferentes tipos de estratégias de resolução de problemas empregadas atualmente através de um diagrama biaxial que as exibe em função de dois atributos: "incertezas dos sistemas" e "decisões em jogo", variando de baixo a elevado, como mostra a Figura 1 (Funtowicz e Ravetz, 1992). Os três intervalos ao longo do eixo horizontal correspondem a diferentes classes de incerteza: técnicas, metodológicas e epistemológicas/ éticas. O eixo vertical relaciona práticas ao mundo das políticas. Por decisões em jogo entendemos, de maneira geral, os custos, benefícios, interesses e compromissos, de qualquer natureza, dos vários apostadores envolvidos numa questão. Configuram-se três zonas que correspondem a três tipos de estratégias de resolução de problemas: ciência aplicada, consultoria profissional e ciência pós-normal. Neste diagrama, a ciência "pura" tradicional estaria localizada na intercessão dos eixos.

Não se tem a pretensão de quantificar nenhum dos atributos que definem as estratégias de resolução de problemas. Eles fornecem parâmetros grosseiros para que se possa aquilatar as distinções entre 
as três zonas. Quando ambos os atributos são mínimos, é adequada a acepção kuhniana de pesquisa, como solução rotineira de um quebra-cabeça. Isso ocorre quando ela fornece informação útil que não é contestada nem é crítica a uma questão de natureza política. Mas quando um dos atributos se acha em nível médio, algo a mais deve ser introduzido no processo, algo que podemos chamar de a habilidade ou o julgamento do profissional. Na consultoria profissional, os atributos podem variar de moderados a agudos. O médico normalmente cuida da saúde ou da vida de um único paciente, mas a tarefa se torna mais complicada em tempos de crise de saúde pública; para o engenheiro se coloca a prosperidade de um cliente, e, no que diz respeito à segurança, o bem-estar de uma comunidade mais ampla. Na ciência pós-normal, quando questões ambientais globais estão em jogo, as apostas podem vir a ser a sobrevivência de uma civilização ou de um ecossistema e, até mesmo, de formas de vida presentes no planeta. $\mathrm{E}$ as incertezas dos sistemas são correlativamente muito mais elevadas.

Uma característica do diagrama é que, mesmo sendo baixas as incertezas, se as decisões em jogo forem elevadas, então a "ciência aplicada" à solução de quebra-cabeças não será eficiente em um processo decisório. Pois nenhum argumento científico pode ser logicamente conclusivo, coisa que mesmo a tradicional filosofia positivista da ciência reconhece. No decurso de um debate científico, os argumentos evolvem no âmbito de um diálogo contínuo que não se consegue reduzir à lógica. O que faz os cientistas 'racionalmente' mudarem suas opiniões é algo que constitui ainda objeto de discussão entre filósofos e sociólogos da ciência. Em debates sobre questões particulares, quando qualquer partido vê seus interesses ameaçados, pode sempre identificar alguma falha metodológica e usá-la para contestar a qualidade do testemunho científico apresentado pelo outro lado. Isso acontece facilmente sobretudo no caso de decisões regulamentadoras de riscos ou do meio ambiente, onde evidências e argumentos são de uma incerteza aguda. Assim, na formulação de políticas, o foro para os debates científicos se alarga de maneira a incluir, além dos aspectos técnicos, todos aqueles interesses comerciais ou corporativos que apostam alto no resultado das decisões.

As tendências que levam a um foro de debate ampliado manifestam-se com mais força ainda no caso da ciência pós-normal. O trabalho de pesquisa e o exercício de habilidades ainda desempenham papel essencial, mas devem transcorrer num arcabouço que integre os problemas científicos circunscritos às questões políticas mais amplas. Dessa forma, recebem direção, têm a qualidade garantida, bem como os meios para obter uma solução negociada de problemas relacionados às políticas em questão, a despeito das complexidades e incertezas inerentes a eles. 
Na safra atual de questões de saúde, acham-se numerosos exemplos de problemas que combinam nível elevado de decisões em jogo com incertezas dos sistemas igualmente elevadas. $\mathrm{Na}$ verdade, a esta categoria de problemas pertence qualquer um dos grandes riscos tecnológicos ou de poluição em larga escala. Caso paradigmático para a ciência pós-normal poderia ser o projeto de um depósito para lixo nuclear longevo que necessitasse permanecer seguro pelos próximos dez mil anos.

A utilidade de nosso diagrama pode ser ilustrada examinandose casos localizados perto de um ou outro eixo. Exemplos de problemas com baixas incertezas dos sistemas podem ser colhidos entre os grandes desastres que se abateram sobre as modernas sociedades industriais em anos recentes. Inquéritos posteriores revelaram, em muitos casos, que o desastre estava "esperando acontecer", por conta de uma combinação de causas predisponentes físicas ou biológicas e práticas administrativas que já eram bem conhecidas de antemão (p. ex., Bhopal, doença da vaca louca). Ainda assim, as ciências aplicadas e consultorias profissionais foram insuficientes para prevenir os acidentes; e o fortalecimento dos regulamentos para impedir que se repitam requer que os desastres se tornem questões políticas que venham a ser resolvidas através da ciência pós-normal.

Caso contrastante é a cosmologia, ciência que hoje (diferentemente dos tempos de Galileu) põe em jogo nível baixo de decisões junto com grau elevado de incertezas. Aqui os dados são tão escassos, as teorias, tão difíceis de testar e o interesse público, tão vívido, que o campo passa a ser "filosofia natural" tanto quanto ciência, e peritos têm de partilhar o palanque com amadores, popularizadores, filósofos e até mesmo teólogos. Neste último exemplo, observamos uma continuidade histórica entre a ciência praticada antes do estabelecimento dos paradigmas autoritários e a ciência pós-normal que emerge no presente. Isso nos ajuda a enxergar a continuidade metodológica que há entre a ciência pós-normal e as outras estratégias de resolução de problemas. Pois a primeira nada mais é que um desenvolvimento de formas tradicionais de ciência adequado às condições da era atual. Seu princípio essencial é que não há mais lugar na ciência e nas decisões políticas que se fundamentam nela para a pretensão de se banir ou subjugar a incerteza e a ignorância. Ao invés disso, cabe administrá-las em proveito do bem comum. Programas para a reforma da tecnologia, da indústria ou do estilo de vida que ignorem esse aspecto do conhecimento científico contemporâneo provavelmente continuarão a fazer parte do problema global ao invés de contribuírem para a solução dele. O uso do diagrama nos permite compreender melhor os diferentes aspectos de projetos complexos em que podem estar presentes os três tipos 
2 Este exemplo foi avalizado em outro artigo para ilustrar classificação análoga dos problemas em científicos, técnicos e práticos (Ravetz, 1971). de prática. Tomemos como exemplo uma represa. ${ }^{2}$ A construção mobilizará muito conhecimento científico básico, aceito; projetos de pesquisa específicos, com caráter de "ciência aplicada", proverão informações sobre aspectos relevantes do meio ambiente local assim como detalhes da futura represa. Mas a construção dela é, em primeiro lugar, um exercício de design, em que a forma e a estrutura não são completamente determinadas pelas informações científicas. No mínimo, o projeto sedimentará um compromisso entre as várias funções possíveis da represa acabada, que poderão incluir armazenamento de água, potência hidrelétrica, controle da corrente de água, irrigação e lazer, com seus respectivos custos. Alcançar o equilíbrio ideal entre esses fatores, levando-se em consideração as incertezas contidas nos aportes científicos e os conflitos de valores entre os vários interesses afetados, é tarefa de uma "consultoria profissional". Mas a questão não se encerra aí. Existe a possibilidade de deterioração a longo prazo do ciclo hidrológico no distrito, de efeitos adversos rio abaixo e talvez até de terremotos localizados. Casas, fazendas e monumentos religiosos podem ser submersos pelo lago artificial. Poderão as pessoas atingidas ser adequadamente recompensadas? Encaradas até há pouco tempo como instrumentos benignos de controle humano da natureza bruta, as represas passaram a ser vistas, de repente, como uma espécie de centralismo predatório praticado por vastas burocracias impessoais contra comunidades nativas e o meio ambiente natural. Quando tais questões estão em jogo, definitivamente já ultrapassamos a consultoria profissional e nos achamos no domínio da ciência pós-normal. Cabe ainda observar que a "complexidade" do projeto da represa não reside, essencialmente, na variedade de disciplinas científicas relevantes (interdisciplinaridade), mas sim na pluralidade de perspectivas legítimas sobre a questão global (transdisciplinaridade).

\section{Comunidades ampliadas de pares}

Também podemos usar o diagrama para ilustrar como um problema se desenvolve na ciência pós-normal até ser subjugado e convertido em algo até certo ponto administrável. Pois, quando se anuncia um perigo ou uma poluição, por exemplo, o problema, quase sempre, se acha em estado de considerável incerteza. Como não foi avaliado previamente, é pouco provável que existam informações substanciais sobre ele. As evidências tenderão a ser anedóticas, pelo lado experimental, e especulativas, pelo lado teórico. Mas a força dos interesses em jogo fará com que todas as partes envolvidas ofereçam suas opiniões em aparência revestidas de absoluta certeza. A primeira fase das discussões se assemelhará, portanto, a um debate político comum, mas de tipo particularmente 
confuso, pois cada lado tentará definir o problema nos termos mais favoráveis a seus interesses e à sua visão de mundo. Os proponentes típicos de uma inovação o apresentarão como objeto retilíneo da ciência aplicada, ao passo que os adversários enfatizarão suas incertezas, complexidades e aspectos éticos (distributivos). É um fenômeno novo a possibilidade de que debates tão amplos sejam eficazes. Até agora a viabilidade comercial ou a segurança do Estado dominaram as considerações acerca do desenvolvimento, deixando algum espaço à preocupação com a saúde, a segurança pública e o meio ambiente. Especialistas treinados de forma tradicional experimentavam sempre perplexidade e consternação ao se confrontarem com quem tentava bloquear o 'progresso' com base em argumentos aparentemente intangíveis e não científicos.

Se tais problemas permanecessem na esfera da pura política de poder seriam assustadoras as perspectivas para as nossas políticas de ciência, tecnologia e saúde. Mas existe um padrão de evolução das questões, no decurso da qual diferentes estratégias de resolução de problemas adquirem proeminência. Isso autoriza a esperança de que a consultoria profissional e também a ciência aplicada possam ainda exercer papel importante. Pois, à medida que o debate se desenvolve e ultrapassa a confusa fase inicial, as posições clarificam-se e novas pesquisas são estimuladas. Embora a definição dos problemas, como vimos, nunca fique livre da política, um diálogo aberto pode permitir que tais considerações não sejam nem unilaterais nem dissimuladas. Na discussão em curso sobre os aspectos técnicos, nenhum dos intercessores precisa admitir que estava errado; basta que ocorra um deslocamento tácito nos termos do debate. E se novas pesquisas eventualmente trouxerem novas informações, a questão pode se tornar mais acessível à abordagem da consultoria profissional e até da ciência aplicada. Assim, por meio do diagrama representando as três estratégias de resolução de problemas, podemos indicar um padrão para a eventual evolução de uma questão complexa e incerta que envolva ciência e política.

É importante ter em mente que a ciência pós-normal é complementar à ciência aplicada e à consultoria profissional. Não substitui as formas tradicionais de ciência, nem contesta o conhecimento científico ou a expertise diplomada postulados em seus contextos legítimos. Filosofias críticas recentes, que enfocam o conhecimento científico alienado de seu contexto social, disseminaram o ponto de vista de que "tudo vale" na ciência (ver, especialmente, Feyerabend, 1975). Nossa análise crítica apóia-se em outras bases, privilegiando o controle de qualidade ou a avaliação crítica. Não se está contestando a perícia técnica de cientistas e profissionais qualificados em esferas de trabalho instituídas. Pode-se 
questionar a qualidade deste trabalho em relação ao problema com que se está lidando, especialmente no tocante a seus aspectos ambientais, sociológicos e éticos. Supunha-se, anteriormente, que esses aspectos eram 'externos' ao trabalho propriamente científico, e que, quando emergiam, uma resposta apropriada seria, de alguma forma, inventada pela 'sociedade'. Agora, a tarefa que se impõe consiste em detectar que tipos de mudanças na prática da ciência, e em suas instituições, serão acarretadas pelo reconhecimento da incerteza, complexidade e qualidade no âmbito das pesquisas relevantes para a formulação de políticas.

$\mathrm{Na}$ ciência, que agora podemos chamar de pré-normal, quase todos os praticantes eram amadores. Podiam debater acaloradamente - e o faziam - todos os aspectos do trabalho, dos dados à metodologia, mas em geral não havia grupo interno de peritos profissionais em conflito com um grupo externo de críticos. $\mathrm{Na}$ ciência normal, os leigos eram efetivamente excluídos do diálogo. Só tinham a chance de serem escutados numa situação "prérevolucionária", tal como Kuhn a definiu, quando o paradigma dominante (cognitivo e social) não se mostrava mais capaz de produzir resultados que lembrassem quebra-cabeças sendo solucionados de maneira estável e progressiva. Na ciência pós-normal ainda se distinguem leigos e especialistas com base - quanto ao conhecimento - na expertise certificada e, socialmente, na ocupação profissional. Mas como os especialistas são freqüentemente incapazes de fornecer soluções conclusivas para os problemas complexos que enfrentam, os leigos conseguem forçar seu ingresso no diálogo. Quando o debate é conduzido perante um público não especializado, os leigos — incluindo membros da comunidade, ecologistas, advogados, legisladores e jornalistas — podem, às vezes, até influenciar a pauta dos temas a debater. Na ciência biomédica, por exemplo, grupos não profissionais dão conselhos sobre questões éticas, e ativistas vêm se juntando ao diálogo acerca do tratamento e até mesmo da pesquisa direcionada para algumas das doenças mais controvertidas de nosso tempo, como a Aids.

Por causa desses aspectos humanos das questões que originam a ciência pós-normal, é necessário ampliar os elementos que constituem o empreendimento científico. Primeiramente, deve incluir uma expertise complementar cujas raízes e filiações residam fora do círculo ao qual pertencem os envolvidos na criação ou regulação oficial do problema. Os novos participantes não apenas enriquecem as comunidades tradicionais de pares, criando o que se pode chamar de "comunidades ampliadas de pares", como são necessários para a transmissão de habilidades e para a garantia da qualidade dos resultados. É importante percebermos que esse fenômeno não é mero resultado das pressões políticas externas que incidem sobre a ciência quando o público está preocupado com 
uma questão ambiental. Na verdade, nas condições em que opera a ciência pós-normal, as funções essenciais de controle de qualidade e avaliação crítica não podem mais ser realizadas plenamente por um corpo restrito de especialistas.

Quando os problemas carecem de soluções límpidas, quando a saúde e a ética sobressaem como aspectos dominantes das questões em pauta, quando os próprios fenômenos são ambíguos e todas as técnicas de pesquisa acham-se expostas à crítica metodológica, então os debates sobre a qualidade não lucram com a exclusão de todos, exceto os pesquisadores especializados e peritos oficiais. Portanto, a ampliação da comunidade de pares não é mero gesto ético ou político. Pode realmente enriquecer os processos de investigação científica. O conhecimento das condições locais ajuda a determinar que dados são consistentes e relevantes, e também a definir os problemas que devem ser alvo das políticas. Tais conhecimentos de caráter local e pessoal não se oferecem naturalmente aos especialistas que atuam em disciplinas determinadas, predispostos pelo treino e emprego a adotarem concepções abstratas e genéricas sobre a legitimidade de problemas e a relevância de informações. As pessoas que dependem da solução de problemas que estão ameaçando suas vidas e sustento têm consciência aguçada de como os princípios gerais se materializam em seus 'quintais'. Também possuem 'fatos ampliados', que incluem anedotas, pesquisas informais e mesmo informações oficiais publicadas em meios não oficiais. Pode-se argumentar que carecem de conhecimentos teóricos e agem parcialmente à luz do interesse próprio; mas também se pode, legitimamente, argumentar que os especialistas carecem de conhecimentos práticos e seguem suas próprias formas inconscientes de tendenciosidade.

Mas a intenção não é apontar qual das comunidades de pares a restrita ou a ampliada - tem conhecimento 'melhor'. Deveríamos, ao contrário, encará-las como complementares, se apoiando e fortalecendo mutuamente. De fato, esse novo tipo de prática põe em perspectiva uma meta nova, mais humanista, para a ciência e a tecnologia. Na ciência pós-normal, enfraquecemos o ideal lógico de predição científica e nos satisfazemos com a meta mais pragmática de "previsão de políticas". Com relação ao conhecimento adquirido, podemos aprimorar a noção tradicional de "explicação científica", convertendo-a em "compreensão societária" bem mais rica. Os novos desafios e a prática emergente da ciência pós-normal podem, assim, engendrar novos ideais para a própria ciência.

\section{Conclusão}

Chegamos a um ponto em que as estratégias tradicionais de resolução de problemas científicos não são mais adequadas às novas 
necessidades. A menos que encontremos um meio de enriquecer a pesquisa, com a inclusão deste novo tipo de prática, não conseguiremos criar métodos para enfrentar toda a complexidade e incerteza dos novos desafios sanitários. Felizmente, estão maduras as condições, sobretudo no que concerne à crescente distribuição social de conhecimentos e habilidades. Nas sociedades modernas, inclusive em algumas daquelas consideradas pobres, existem já amplos eleitorados formados por pessoas comuns que sabem ler, escrever, votar e debater. A democratização da vida política tornou-se lugar comum. Seus riscos são aceitos como preço pequeno a pagar pelos benefícios. Agora está se tornando possível alcançar a democratização paralela dos conhecimentos não apenas na educação institucional de massa, como também na maior participação nas decisões, visando o gerenciamento mais sábio de nossos poderes científicos.

A democratização desse aspecto da ciência não é fruto da benevolência dos grupos estabelecidos, e sim (como na esfera da política) realização de um sistema que, a despeito de suas ineficiências, é o meio mais eficaz de se evitar os desastres que resultam do abafamento prolongado da crítica. A experiência recente mostrou que a presença da crítica é tão importante para nossas questões tecnológicas e ambientais quanto para a sociedade. Sejamos bem claros com relação a isso. O que nos leva a argumentar em favor da democratização da ciência não é um desejo genérico de estender ao máximo a democracia na sociedade. A análise epistemológica da ciência pós-normal, enraizada nas tarefas práticas do controle de qualidade, mostra que tal ampliação das comunidades de pares, com a correspondente extensão dos fatos, é necessária para tornar a ciência capaz de enfrentar os novos desafios apresentados por complexos problemas ambientais.

\section{REFERÊNCIAS BIBLIOGRÁFICAS}

Feyerabend, P. K. 1975

Funtowicz, S. O e Ravetz, J. R. 1992

Funtowicz, S. O e Ravetz, J. R. 1990

Kuhn, T. S. 1962

Latour, Bruno. 1988

Ravetz, J. R. $1971 / 1996$
Against method.

Londres, New Left Books.

'Three types of risk assessment and the emergence of post-normal science'. Em D. Golding e S. Krimsky (orgs.), Social theories of risk. Nova York, Greenwood Press, pp. 251-73.

Uncertainty and quality in science for policy. Dordrecht, Kluwer.

The structure of scientific revolutions. Chicago, Universidade de Chicago.

The pasteurization of France. Cambridge, Massachusetts., Harvard University Press.

Scientific knowledge and its social problems. Londres, Transaction Publishers.

Recebido para publicação em julho de 1997 